\title{
THE DESIGN OF SHELL AND TUBE HEAT EXCHANGERS - A REVIEW
}

\section{KARTHIK SILAIPILLAYARPUTHUR \& HASSAN KHURSHID}

Department of Mechanical Engineering, King Faisal University, Al Ahsaa, Saudi Arabia

\begin{abstract}
The paper considered a review for the design of a shell and tube heat exchanger. Therein, popular analytical techniques such as log mean temperature difference (LMTD) and effectiveness-number of transfer units (E-NTU) were considered in the analysis. In the design, analysis, performance charts and tables describing the performance of the shell and tube heat exchanger in terms of crucial dimensionless parameters were developed. These fundamental dimensionless parameters account for the thermal \& the physical properties of the fluids and the heat exchanger (HX) material. Using the information from the performance charts and tables, a basic design for the shell and tube heat exchanger can be readily formulated. The basic design involves choosing an appropriate number of transfer units (NTU) and capacity rate ratio for a given application. The $N T U$ and capacity rate ratio can then be extrapolated to develop a detailed design for the shell and tube heat exchanger. Since NTU and capacity rate ratio accounts for all the significant physical and thermal properties of the heat exchanger, performance tables and charts would certainly help in maximizing the performance and minimizing the cost of the shell and tube heat exchanger. In the case considered herein, both LMTD and E-NTU techniques yield the same exact results.

KEYWORDS: Shell and Tube Heat Exchanger Design, Performance Tables and Performance Charts for Shell \& Tube Heat Exchanger
\end{abstract}

Received: Oct 04, 2018; Accepted: Oct 24, 2018; Published: Dec 26, 2018; Paper Id.: IJMPERDFEB201910

\section{INTRODUCTION}

Heat exchangers are widely used in manufacturing and process industries for several applications. The choice of heat exchanger for a given application is dependent on several factors such as the application, available floor area, available resources, connections in the field, cost, and many more. In a highly competitive environment, it is essential that the heat exchanger must deliver the required heat transfer, occupy less space, weigh less, and yet be priced competitively.

In this project, a shell and tube heat exchanger is designed for heating hot oil. Hot oil is used for a certain process heating application and steam is the heating medium. The heat exchanger shall be designed such that the hot oil flows through the tubes and steam through the shell side of the heat exchanger. It is assumed that large steam flow rate is available to provide the required heating for the hot oil in the shell and tube heat exchanger. A conventional $\varepsilon$-NTU approach and LMTD approach shall be used to design the shell and tube heat exchanger. Performance tables and charts describing the variation of shell and tube heat exchanger's performance with respect to capacity rate ratio and NTU were developed. Dimensionless parameters such as capacity rate ratio and NTU provide concise information on the heat exchanger as they account for material characteristics, flow characteristics, physical and thermal properties, construction and fouling. Likewise, the developed tables and charts can also be employed during the regular working phase of the shell and tube heat exchanger to understand its performance and 
to schedule any required maintenance activities.

There are numerous references available in the literature pertaining to heat exchanger performance modelling, and only the most pertinent studies are discussed in this manuscript. Tahery et al [1] considered new design techniques based on the tube bundle effect in the economic optimization of shell-and-tube heat exchangers. They developed cost estimation techniques for shell-and-tube heat exchangers by introducing new objective functions. The combined reduction of annual capital investment and operating cost led to a decrease in the overall costs of about $10 \%$ to $24 \%$. Hadidi et al [2] considered cost minimization of shell-and-tube heat exchangers. They developed a new shell and tube heat exchanger optimization approach based on an imperialist competitive algorithm (ICA). ICA technique was applied to minimize the total cost of the equipment. Based on proposed method, a full computer code was developed for optimal design of shell and tube heat exchangers and different test cases were solved to demonstrate the effectiveness and accuracy of the proposed algorithm. The results from the study indicated that the ICA algorithm can be successfully applied for optimal design of shell and tube heat exchangers. Sencan et al [3] discussed a new shell and tube heat exchanger optimization design approach. Artificial Bee Colony (ABC) was applied to minimize the total cost of the equipment including capital investment and the sum of discounted annual energy expenditures. The results were compared to those obtained by literature approaches. The obtained results indicated that Artificial Bee Colony (ABC) algorithm can be successfully applied for optimal design of shell and tube heat exchangers. Eryener [4] considered the optimization of baffle spacing for shell and tube heat exchangers. Thermoeconomic analysis was used to determine the optimum baffle spacing for a shell and tube heat exchanger. The results from the approach were compared to those obtained by classical approaches. Azar et al [5] suitably modified the existing heat transfer and pressure drop correction factors of the modified Bell-Delaware method and used for heat exchangers with segmental baffles, taking into consideration the helical baffle geometry. These correction factors were present in parametric formulas for segmented baffles. These formulas are functions of the geometrical and physical parameters of discontinuous helical baffles. The parametric formulas were presented graphically as well. In order to calculate the shell-side heat transfer coefficient and pressure drop using the present method, a computational code was developed. The results from the study showed that the proposed method was accurate and can be used by designers confidently.

Muralikrishna and Shenoy [6] proposed a methodology to determine the feasible region for shell and tube heat exchanger designs on a pressure drop diagram. By accounting for operating as well as geometrical constraints, the feasible region is defined so as to eliminate trial-and-error during the design activity. Every point on, the plot of shell side versus tube side pressure drop corresponds to a unique design in terms of tube length, shell diameter and baffle spacing. Furthermore, curves may be plotted for designs corresponding to a specified heat exchange area or a given total annual cost. Caputo et al [7] considered a procedure for optimal design of shell and tube heat exchangers, which utilizes a genetic algorithm to minimize the total cost of the equipment including capital investment and the sum of discounted annual energy expenditures related to pumping. In order to verify the capability of the proposed method, three case studies were presented showing significant cost reductions. In particular, in the examined cases a reduction of total costs up to more than $50 \%$ was observed. Serna and JimEnez [8] presented a simple, rapid, and robust algorithm for the design of segmentally baffled shell and tube heat exchangers. The core of the algorithm was provided by two compact formulations that relate the pressure drop for each side of the exchanger with the film heat transfer coefficient and the exchanger area. The compact formula for the tube side includes the effects of tube ends while the one for the shell side is based on the Bell-Delaware method. 
The parameters of the compact formulas were used as search variables in the design algorithm. Wang et al [9] presented a general review of developments and improvements on helixchangers, which includes the discontinuous helical baffles, continuous or combined helical baffles, and the combined multiple shell-pass helixchangers. Extensive results from experiments and numerical simulations indicated that the helixchangers have better flow and heat transfer performance than the conventional segmental baffled heat exchangers. Based on the new improvements, the conventional heat exchangers with segmental baffles might be replaced by helixchangers in industrial applications to save energy, reduce cost, and prolong the service life and operation time. Bell [10] considered the design process for heat exchangers in the process industries and for similar applications in the power and large-scale environmental control industries. Many different exchanger configurations are commercially available to meet special conditions, with design procedures of varying degrees of reliability. A general design logic can be applied, with detailed procedures specific to the type of exchanger. The emphasis in choosing a design method is upon rational representation of the physical processes, rather than upon high accuracy. Silaipillayarputhur et al [11] considered the design of the concentric tube heat exchanger wherein sensible heat transfer was considered between the two fluids. Performance charts for concentric tube heat exchanger were developed, and such charts are useful in designing an economical heat exchanger. Silaipillayarputhur, K and Al Mughanam [12] investigated the steady state sensible performance of multi pass parallel cross flow exchangers. Therein, the multi pass heat exchanger's performance was expressed through performance charts. Performance charts describe the performance of the heat exchanger in terms of pertinent dimensionless parameters such as capacity rate ratio, number of transfer units (NTU) and heat exchanger effectiveness.

\section{NOMENCLATURE}

\begin{tabular}{cl}
$\begin{array}{c}\text { Symbol } \\
A\end{array}$ & \multicolumn{1}{c}{ Name } \\
$\mathrm{C}_{\min }$ & minimum capacity rate $(\mathrm{W} / \mathrm{K})$ \\
$\mathrm{C}_{\mathrm{max}}$ & maximum capacity rate $(\mathrm{W} / \mathrm{K})$ \\
$\mathrm{C}_{\mathrm{r}}$ & capacity rate ratio (dimensionless) \\
$\mathrm{c}_{\mathrm{p}}$ & specific heat at constant pressure $(\mathrm{J} / \mathrm{kg} \cdot \mathrm{K})$ \\
$\mathrm{D}$ & tube diameter $(\mathrm{m})$ \\
$\mathrm{D}_{\mathrm{b}}$ & tube bundle diameter $(\mathrm{m})$ \\
$\mathrm{D}_{\mathrm{si}}$ & shell inside diameter $(\mathrm{m})$ \\
$\mathrm{h}_{\mathrm{i}}$ & internal heat transfer coefficient $\left(\mathrm{W} / \mathrm{m}^{2} \mathrm{~K}\right)$ \\
$\mathrm{h}_{\mathrm{o}}$ & external heat transfer coefficient $\left(\mathrm{W} / \mathrm{m}^{2} \mathrm{~K}\right)$ \\
$\mathrm{m}$ & mass flow rate $(\mathrm{kg} / \mathrm{s})$ \\
$\mathrm{K}_{1}$ & constant for tube bundle diameter \\
$\mathrm{k}$ & (dimensionless) \\
Greek Symbols & thermal conductivity $(\mathrm{W} / \mathrm{mK})$ \\
$\varepsilon$ & heat exchanger effectiveness \\
$\mu$ & (dimensionless) \\
$\rho$ & dynamic viscosity $\left(\mathrm{N}-\mathrm{s} / \mathrm{m}^{2}\right)$ \\
& density (kg/m $\left.{ }^{3}\right)$
\end{tabular}

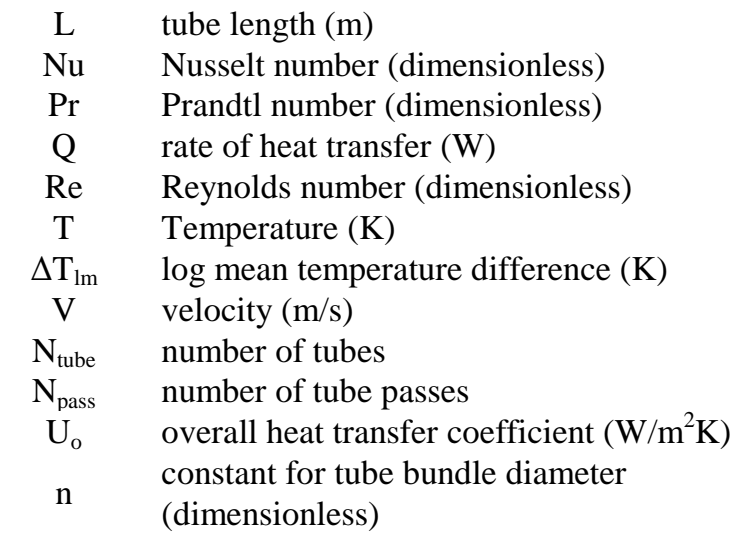

$\begin{array}{cl}\text { Subscripts } & \\ \text { i } & \text { inner } \\ \text { o } & \text { outer } \\ \text { W } & \text { wall }\end{array}$

\section{Governing Equations}

This project considers the design of a shell and tube heat exchanger wherein the hot oil is in the tube side of the heat exchanger and steam is on the shell side of the heat exchanger. Steam is available from the powerhouse and as in any process plant, it is assumed that large mass flow rate of steam is available for heating purposes. 
The hot oil employed in the study is a Conoco diamond class heat transfer fluid, rated for open systems, having a viscosity grade of ISO 46. Table 1 describes the properties of the hot oil. It is desired to raise the temperature of 50 GPM (gallons/minute) of hot oil from $170^{\circ} \mathrm{F}$ to $200^{\circ} \mathrm{F}$ by employing $300 \mathrm{lb} / \mathrm{in}^{2}$ saturated steam. Table 1 describes the properties of the hot oil.

Table 1: Hot Oil Thermal Properties

\begin{tabular}{|c|c|c|c|c|}
\hline \multicolumn{5}{|c|}{ Hot Oil Thermal Properties } \\
\hline $\boldsymbol{\rho}\left(\mathbf{k g} / \mathbf{m}^{\mathbf{3}}\right)$ & $\dot{m}(k g / s)$ & $\mathbf{C}_{\mathbf{P}}\left(\mathbf{J} / \mathbf{k g}^{\mathbf{0}} \mathbf{C}\right)$ & $\mathbf{k}\left(\mathbf{W} / \mathbf{m}^{\mathbf{0}} \mathbf{C}\right)$ & $\boldsymbol{\mu}\left(\mathbf{N}-\mathbf{s} / \mathbf{m}^{2}\right)$ \\
\hline 761 & 3.15 & 2558 & 0.133 & 0.00117 \\
\hline
\end{tabular}

Conventional $\varepsilon$-NTU approach and LMTD approach are applied in the design of shell and tube hot oil heat exchanger. The rate of sensible heat transfer or the heat gained by hot oil can be described as follows [13]

$$
\mathrm{Q}_{\mathrm{oil}}=\dot{\mathrm{mc}} \mathrm{p}\left(\mathrm{T}_{2}-\mathrm{T}_{1}\right)
$$

Herein, $\mathrm{T}_{1}$ and $\mathrm{T}_{2}$ correspond to inlet and discharge temperatures of the hot oil. Assuming the shell and tube heat exchanger to be well insulated it can be assumed that the rate of heat gained by the hot oil will be equal to rate of heat loss in steam such that

$$
\mathrm{Q}=\mathrm{Q}_{\text {oil }}=\mathrm{Q}_{\text {steam }}
$$

Since the steam on the shell side of the heat exchanger is assumed to undergo phase change from saturated vapor to saturated liquid, steam has the maximum heat capacity rate and the value tends to infinity. The capacity rate ratio may be given as [13]

$$
\mathrm{C}_{\mathrm{r}}=\frac{\mathrm{C}_{\min }}{\mathrm{C}_{\max }}
$$

In the above equation, $\mathrm{C}_{\min }$ corresponds to the capacity rate of minimum capacity rate fluid, which is the hot oil. Since $\mathrm{C}_{\max }$ tends to infinity, for the given arrangement, the capacity rate ratio is 0 . The heat exchanger effectiveness may then be determined by employing the following equation [13]

$$
\varepsilon=\frac{\mathrm{Q}}{\mathrm{Q}_{\max }}=\frac{\mathrm{Q}}{\mathrm{C}_{\text {min }}\left[\mathrm{T}_{\text {steam }}-\mathrm{T}_{\text {oil,inlet }}\right.}
$$

Here, the rate of heat transfer $\mathrm{Q}$ is given by Equation (1). The heat exchanger effectiveness for a shell and tube heat exchanger having one shell pass and multiple tube passes may be given as [13]

$$
\varepsilon_{1}=2\left\{1+\mathrm{C}_{\mathrm{r}}+\left(1+\mathrm{C}_{\mathrm{r}}^{2}\right)^{\frac{1}{2}} * \frac{1+\exp \left[-(\mathrm{NTU})_{1}\left(1+\mathrm{C}_{\mathrm{r}}^{2}\right)^{\frac{1}{2}}\right]}{1-\exp \left[-(\mathrm{NTU})_{1}\left(1+\mathrm{C}_{\mathrm{r}}^{2}\right)^{\frac{1}{2}}\right]}\right\}^{-1}
$$

and: 


$$
\mathrm{NTU}_{1}=\frac{\mathrm{NTU}}{\mathrm{n}}
$$

Where $\mathrm{n}$ corresponds to the number of shell passes. Likewise, for a heat exchanger having multiple shell passes and multiple tube passes, the overall heat exchanger effectiveness may be given as [13]

$$
\varepsilon=\left[\left(\frac{1-\varepsilon_{1} C_{r}}{1-\varepsilon_{1}}\right)^{n}-1\right]\left[\left(\frac{1-\varepsilon_{1} C_{r}}{1-\varepsilon_{1}}\right)^{n}-C_{r}\right]^{-1}
$$

Number of transfer units (NTU) is a dimensionless parameter that is widely used by process engineers and heat exchanger designers. As stated before, NTU is a physically significant dimensionless parameter as it accounts for material characteristics, fluid characteristics, flow characteristics, thermal characteristics, heat exchanger size, fouling, etc. Using Equations $(5,6$, and 7$)$, for a range of NTU varying from 0.1 to 10 , the heat exchanger effectiveness was plotted as a function of capacity rate ratio. The capacity rate ratio varies between 0 and 1 . The NTU range selected for this study is the commonly working range seen in the process industries.

Consider Figure 1 through 3 and Tables 2 through 4 describing the performance charts and tables for a shell and tube heat exchanger. With the available inputs and the desired output, the heat exchanger's required effectiveness can be readily computed. Thereafter, using the charts and tables, a reasonable NTU and capacity rate ratio that would satisfy the required heat exchanger effectiveness can be selected. Subsequently, NTU and capacity rate ratio can be extrapolated using LMTD and/or $\varepsilon$-NTU approach to yield the detailed design of the heat exchanger.

The developed tables and charts will certainly help the engineers in determining the right heat exchanger for the given application. A heat exchanger operating with a NTU below than the required will certainly struggle to maintain the desired output. Likewise, a heat exchanger operating with a NTU much more than the required will cost more. Higher NTU correspond to larger surface area, which corresponds to more material, weight and cost. Thus, optimizing the design based on NTU is a very important activity during the initial design of the heat exchanger. Likewise, materials that are of light weight, easy to fabricate and having high thermal conductivity can be chosen while accounting for the NTU of the heat exchanger.

Similarly, during the regular heat exchanger operation, due to fouling, the performance of the heat exchanger gradually reduces over a time period. It is often a tricky exercise to plan the required maintenance work as the shutdown of the heat exchanger equipment usually affects the production in the process industry. However, having the performance tables and charts on hand, the engineers can readily trend the performance of the heat exchanger equipment with respect to the design point. In-addition, to keep up with the varying demands in production, the heat exchanger operation set point requires to be adjusted all the time. It is a usual practice to leave the control systems to handle such changes. Nevertheless, having performance tables and charts on hand will alert the engineers ahead of time on whether it is practically feasible for the heat exchanger to deliver the requirements when subjected to such changes in the inputs and operational set points.

The heat exchanger effectiveness, NTU and capacity rate ratio are dimensionless, universal, and are applied across the globe while designing heat exchangers. The charts and tables are developed from the fundamental analytical relationships and hence can be used as a benchmark to validate a heat exchanger equipment. 


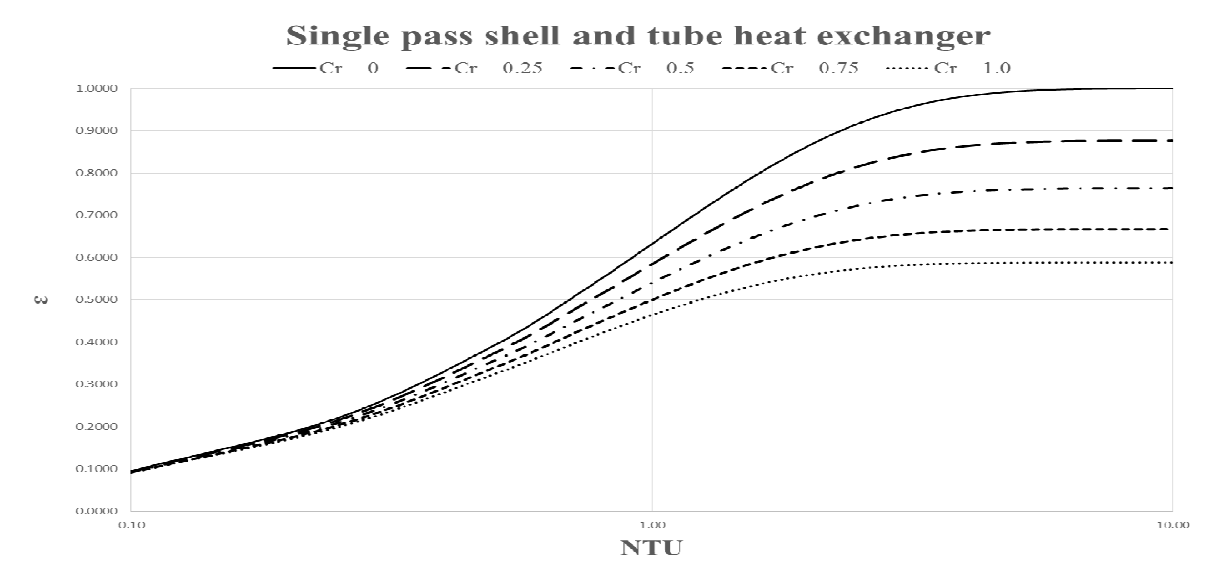

Figure 1: Performance of a 1 Shell Pass and 2,4,6,.. Tube Passes Heat Exchanger

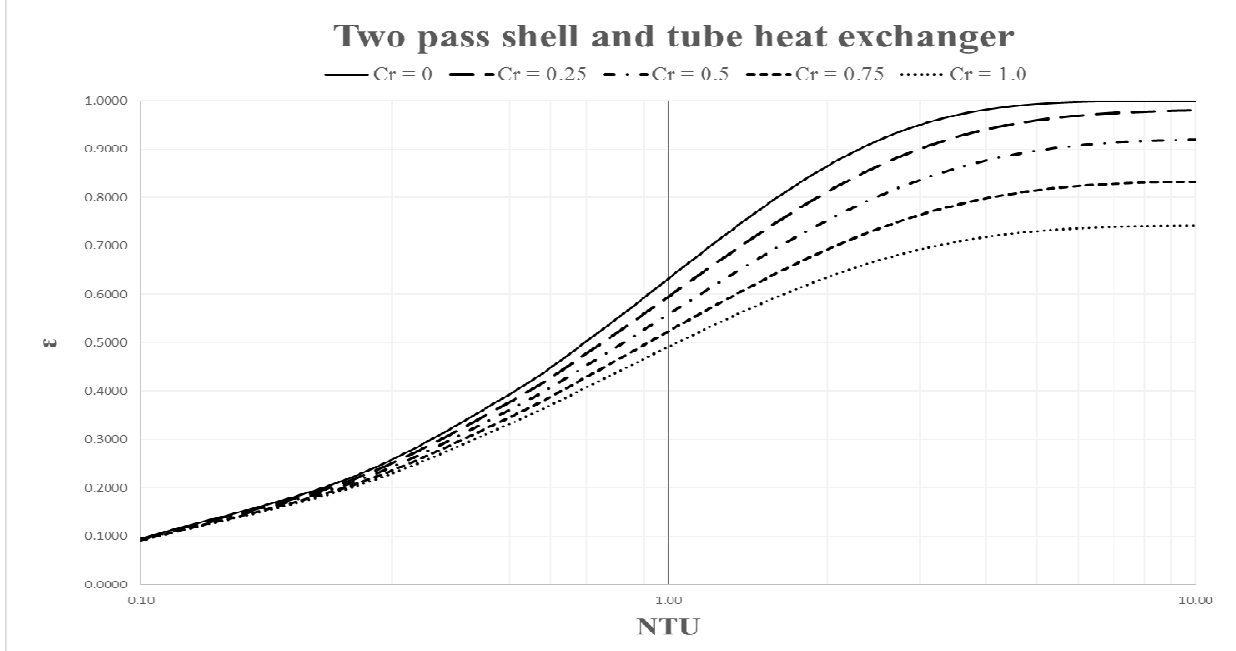

Figure 2: Performance of a 2 Shell Passes and 4,8,12... Tube Passes Heat Exchanger

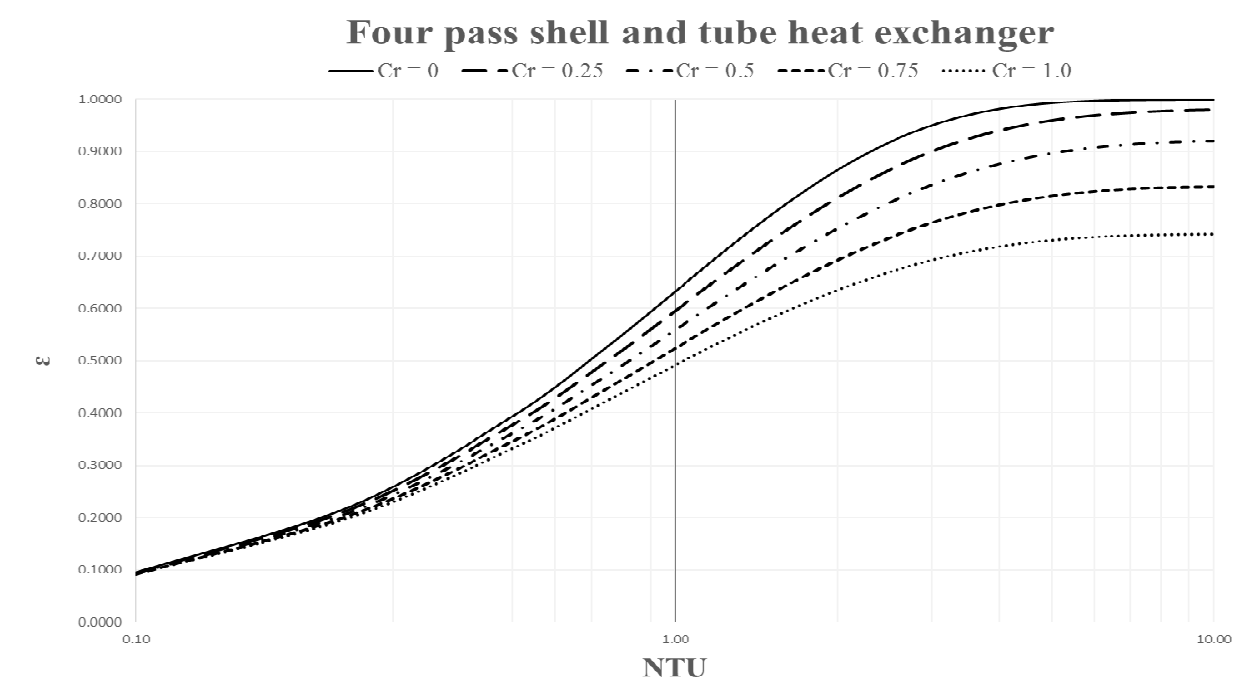

Figure 3: Performance of a 4 Shell Passes and 8,16,24... Tube Passes Heat Exchanger 
Table 1: Performance Tables for Shell and Tube Heat Exchanger $\left(C_{r}=0 ; C_{r}=0.25\right)$

\begin{tabular}{|c|c|c|c|c|}
\hline \multicolumn{5}{|c|}{ Cr= } \\
\hline NTU & Cr & $\boldsymbol{\varepsilon}$ & $\boldsymbol{\varepsilon}$ & $\boldsymbol{\varepsilon}$ \\
\hline & & 1 Shell Pass & 2 Shell Passes & 4 Shell Passes \\
\hline 0.10 & 0 & 0.0952 & 0.0952 & 0.0952 \\
\hline 0.25 & 0 & 0.2212 & 0.2212 & 0.2212 \\
\hline 0.50 & 0 & 0.3935 & 0.3935 & 0.3935 \\
\hline 0.75 & 0 & 0.5276 & 0.5276 & 0.5276 \\
\hline 1.00 & 0 & 0.6321 & 0.6321 & 0.6321 \\
\hline 1.25 & 0 & 0.7135 & 0.7135 & 0.7135 \\
\hline 1.50 & 0 & 0.7769 & 0.7769 & 0.7769 \\
\hline 1.75 & 0 & 0.8262 & 0.8262 & 0.8262 \\
\hline 2.00 & 0 & 0.8647 & 0.8647 & 0.8647 \\
\hline 2.25 & 0 & 0.8946 & 0.8946 & 0.8946 \\
\hline 2.50 & 0 & 0.9179 & 0.9179 & 0.9179 \\
\hline 2.75 & 0 & 0.9361 & 0.9361 & 0.9361 \\
\hline 3.00 & 0 & 0.9502 & 0.9502 & 0.9502 \\
\hline 3.25 & 0 & 0.9612 & 0.9612 & 0.9612 \\
\hline 3.50 & 0 & 0.9698 & 0.9698 & 0.9698 \\
\hline 3.75 & 0 & 0.9765 & 0.9765 & 0.9765 \\
\hline 4.00 & 0 & 0.9817 & 0.9817 & 0.9817 \\
\hline 4.25 & 0 & 0.9857 & 0.9857 & 0.9857 \\
\hline 4.50 & 0 & 0.9889 & 0.9889 & 0.9889 \\
\hline 4.75 & 0 & 0.9913 & 0.9913 & 0.9913 \\
\hline 5.00 & 0 & 0.9933 & 0.9933 & 0.9933 \\
\hline 5.25 & 0 & 0.9948 & 0.9948 & 0.9948 \\
\hline 5.50 & 0 & 0.9959 & 0.9959 & 0.9959 \\
\hline 5.75 & 0 & 0.9968 & 0.9968 & 0.9968 \\
\hline 6.00 & 0 & 0.9975 & 0.9975 & 0.9975 \\
\hline 6.25 & 0 & 0.9981 & 0.9981 & 0.9981 \\
\hline 6.50 & 0 & 0.9985 & 0.9985 & 0.9985 \\
\hline 6.75 & 0 & 0.9988 & 0.9988 & 0.9988 \\
\hline 7.00 & 0 & 0.9991 & 0.9991 & 0.9991 \\
\hline 7.25 & 0 & 0.9993 & 0.9993 & 0.9993 \\
\hline 7.50 & 0 & 0.9994 & 0.9994 & 0.9994 \\
\hline 7.75 & 0 & 0.9996 & 0.9996 & 0.9996 \\
\hline 8.00 & 0 & 0.9997 & 0.9997 & 0.9997 \\
\hline 8.25 & 0 & 0.9997 & 0.9997 & 0.9997 \\
\hline 8.50 & 0 & 0.9998 & 0.9998 & 0.9998 \\
\hline 8.75 & 0 & 0.9998 & 0.9998 & 0.9998 \\
\hline 9.00 & 0 & 0.9999 & 0.9999 & 0.9999 \\
\hline 9.25 & 0 & 0.9999 & 0.9999 & 0.9999 \\
\hline 9.50 & 0 & 0.9999 & 0.9999 & 0.9999 \\
\hline 9.75 & 0 & 0.9999 & 0.9999 & 0.9999 \\
\hline 10.00 & 0 & 1.0000 & 1.0000 & 1.0000 \\
\hline & & & & \\
\hline
\end{tabular}

\begin{tabular}{|c|c|c|c|c|}
\hline \multicolumn{5}{|c|}{ Cr $=\mathbf{0 . 2 5}$} \\
\hline NTU & Cr & $\boldsymbol{\varepsilon}$ & $\boldsymbol{\varepsilon}$ & $\boldsymbol{\varepsilon}$ \\
\hline & & $\mathbf{1}$ Shell Pass & 2 Shell Passes & 4 Shell Passes \\
\hline 0.10 & 0.25 & 0.0940 & 0.0941 & 0.0941 \\
\hline 0.25 & 0.25 & 0.2152 & 0.2155 & 0.2155 \\
\hline 0.50 & 0.25 & 0.3747 & 0.3769 & 0.3769 \\
\hline 0.75 & 0.25 & 0.4940 & 0.4998 & 0.4998 \\
\hline 1.00 & 0.25 & 0.5841 & 0.5947 & 0.5947 \\
\hline 1.25 & 0.25 & 0.6524 & 0.6689 & 0.6689 \\
\hline 1.50 & 0.25 & 0.7045 & 0.7274 & 0.7274 \\
\hline 1.75 & 0.25 & 0.7473 & 0.7738 & 0.7738 \\
\hline 2.00 & 0.25 & 0.7748 & 0.8109 & 0.8109 \\
\hline 2.25 & 0.25 & 0.7982 & 0.8407 & 0.8407 \\
\hline 2.50 & 0.25 & 0.8162 & 0.8648 & 0.8648 \\
\hline 2.75 & 0.25 & 0.8301 & 0.8844 & 0.8844 \\
\hline 3.00 & 0.25 & 0.8408 & 0.9003 & 0.9003 \\
\hline 3.25 & 0.25 & 0.8490 & 0.9134 & 0.9134 \\
\hline 3.50 & 0.25 & 0.8553 & 0.9241 & 0.9241 \\
\hline 3.75 & 0.25 & 0.8603 & 0.9330 & 0.9330 \\
\hline 4.00 & 0.25 & 0.8640 & 0.9403 & 0.9403 \\
\hline 4.25 & 0.25 & 0.8670 & 0.9464 & 0.9464 \\
\hline 4.50 & 0.25 & 0.8692 & 0.9516 & 0.9516 \\
\hline 4.75 & 0.25 & 0.8710 & 0.9559 & 0.9559 \\
\hline 5.00 & 0.25 & 0.8723 & 0.9595 & 0.9595 \\
\hline 5.25 & 0.25 & 0.8734 & 0.9625 & 0.9625 \\
\hline 5.50 & 0.25 & 0.8742 & 0.9651 & 0.9651 \\
\hline 5.75 & 0.25 & 0.8748 & 0.9673 & 0.9673 \\
\hline 6.00 & 0.25 & 0.8753 & 0.9692 & 0.9692 \\
\hline 6.25 & 0.25 & 0.8756 & 0.9708 & 0.9708 \\
\hline 6.50 & 0.25 & 0.8759 & 0.9722 & 0.9722 \\
\hline 6.75 & 0.25 & 0.8761 & 0.9734 & 0.9734 \\
\hline 7.00 & 0.25 & 0.8763 & 0.9744 & 0.9744 \\
\hline 7.25 & 0.25 & 0.8764 & 0.9753 & 0.9753 \\
\hline 7.50 & 0.25 & 0.8765 & 0.9760 & 0.9760 \\
\hline 7.75 & 0.25 & 0.8766 & 0.9767 & 0.9767 \\
\hline 8.00 & 0.25 & 0.8767 & 0.9773 & 0.9773 \\
\hline 8.25 & 0.25 & 0.8767 & 0.9778 & 0.9778 \\
\hline 8.50 & 0.25 & 0.8768 & 0.9782 & 0.9782 \\
\hline 8.75 & 0.25 & 0.8768 & 0.9786 & 0.9786 \\
\hline 9.00 & 0.25 & 0.8768 & 0.9789 & 0.9789 \\
\hline 9.25 & 0.25 & 0.8768 & 0.9792 & 0.9792 \\
\hline 9.50 & 0.25 & 0.8769 & 0.9795 & 0.9795 \\
\hline 9.75 & 0.25 & 0.8769 & 0.9797 & 0.9797 \\
\hline 10.00 & 0.25 & 0.8769 & 0.9799 & 0.9799 \\
\hline & & & & \\
\hline
\end{tabular}

Table 2: Performance Tables for Shell and Tube Heat Exchanger $\left(C_{r}=0.5 ; C_{r}=0.75\right)$

\begin{tabular}{|c|c|c|c|c|}
\hline \multicolumn{5}{|c|}{ Cr= 0.5} \\
\hline NTU & Cr & $\boldsymbol{\varepsilon}$ & $\boldsymbol{\varepsilon}$ & $\boldsymbol{\varepsilon}$ \\
\hline & & 1 Shell Pass & 2 Shell Passes & 4 Shell Passes \\
\hline 0.10 & 0.5 & 0.0929 & 0.0930 & 0.0930 \\
\hline 0.25 & 0.5 & 0.2094 & 0.2101 & 0.2101 \\
\hline 0.50 & 0.5 & 0.3569 & 0.3609 & 0.3609 \\
\hline 0.75 & 0.5 & 0.4628 & 0.4730 & 0.4730 \\
\hline 1.00 & 0.5 & 0.5399 & 0.5583 & 0.5583 \\
\hline 1.25 & 0.5 & 0.5966 & 0.6246 & 0.6246 \\
\hline 1.50 & 0.5 & 0.6385 & 0.6768 & 0.6768 \\
\hline 1.75 & 0.5 & 0.6698 & 0.7186 & 0.7186 \\
\hline 2.00 & 0.5 & 0.6931 & 0.7522 & 0.7522 \\
\hline 2.25 & 0.5 & 0.7106 & 0.7796 & 0.7796 \\
\hline 2.50 & 0.5 & 0.7237 & 0.8020 & 0.8020 \\
\hline 2.75 & 0.5 & 0.7336 & 0.8205 & 0.8205 \\
\hline 3.00 & 0.5 & 0.7410 & 0.8359 & 0.8359 \\
\hline 3.25 & 0.5 & 0.7466 & 0.8487 & 0.8487 \\
\hline 3.50 & 0.5 & 0.7509 & 0.8594 & 0.8594 \\
\hline 3.75 & 0.5 & 0.7541 & 0.8684 & 0.8684 \\
\hline 4.00 & 0.5 & 0.7565 & 0.8760 & 0.8760 \\
\hline 4.25 & 0.5 & 0.7583 & 0.8825 & 0.8825 \\
\hline 4.50 & 0.5 & 0.7597 & 0.8879 & 0.8879 \\
\hline 4.75 & 0.5 & 0.7607 & 0.8926 & 0.8926 \\
\hline 5.00 & 0.5 & 0.7615 & 0.8966 & 0.8966 \\
\hline 5.25 & 0.5 & 0.7621 & 0.9000 & 0.9000 \\
\hline 5.50 & 0.5 & 0.7625 & 0.9029 & 0.9029 \\
\hline 5.75 & 0.5 & 0.7629 & 0.9054 & 0.9054 \\
\hline 6.00 & 0.5 & 0.7631 & 0.9075 & 0.9075 \\
\hline 6.25 & 0.5 & 0.7633 & 0.9094 & 0.9094 \\
\hline 6.50 & 0.5 & 0.7635 & 0.9110 & 0.9110 \\
\hline 6.75 & 0.5 & 0.7636 & 0.9124 & 0.9124 \\
\hline 7.00 & 0.5 & 0.7637 & 0.9136 & 0.9136 \\
\hline 7.25 & 0.5 & 0.7637 & 0.9146 & 0.9146 \\
\hline 7.50 & 0.5 & 0.7638 & 0.9155 & 0.9155 \\
\hline 7.75 & 0.5 & 0.7638 & 0.9163 & 0.9163 \\
\hline 8.00 & 0.5 & 0.7638 & 0.9169 & 0.9169 \\
\hline 8.25 & 0.5 & 0.7639 & 0.9175 & 0.9175 \\
\hline 8.50 & 0.5 & 0.7639 & 0.9180 & 0.9180 \\
\hline 8.75 & 0.5 & 0.7639 & 0.9184 & 0.9184 \\
\hline 9.00 & 0.5 & 0.7639 & 0.9188 & 0.9188 \\
\hline 9.25 & 0.5 & 0.7639 & 0.9191 & 0.9191 \\
\hline 9.50 & 0.5 & 0.7639 & 0.9194 & 0.9194 \\
\hline 9.75 & 0.5 & 0.7639 & 0.9197 & 0.9197 \\
\hline 10.00 & 0.5 & 0.7639 & 0.9199 & 0.9199 \\
\hline & & & & \\
\hline
\end{tabular}

\begin{tabular}{|c|c|c|c|c|}
\hline \multicolumn{5}{|c|}{ Cr= 0.75} \\
\hline NTU & Cr & $\varepsilon$ & $\varepsilon$ & $\varepsilon$ \\
\hline & & 1 Shell Pass & 2 Shell Passes & 4 Shell Passes \\
\hline 0.10 & 0.75 & 0.0918 & 0.0919 & 0.0919 \\
\hline 0.25 & 0.75 & 0.2038 & 0.2047 & 0.2047 \\
\hline 0.50 & 0.75 & 0.3402 & 0.3456 & 0.3456 \\
\hline 0.75 & 0.75 & 0.4339 & 0.4473 & 0.4473 \\
\hline 1.00 & 0.75 & 0.4995 & 0.5233 & 0.5233 \\
\hline 1.25 & 0.75 & 0.5460 & 0.5814 & 0.5814 \\
\hline 1.50 & 0.75 & 0.5792 & 0.6269 & 0.6269 \\
\hline 1.75 & 0.75 & 0.6031 & 0.6629 & 0.6629 \\
\hline 2.00 & 0.75 & 0.6204 & 0.6918 & 0.6918 \\
\hline 2.25 & 0.75 & 0.6330 & 0.7153 & 0.7153 \\
\hline 2.50 & 0.75 & 0.6421 & 0.7345 & 0.7345 \\
\hline 2.75 & 0.75 & 0.6487 & 0.7503 & 0.7503 \\
\hline 3.00 & 0.75 & 0.6535 & 0.7634 & 0.7634 \\
\hline 3.25 & 0.75 & 0.6571 & 0.7743 & 0.7743 \\
\hline 3.50 & 0.75 & 0.6597 & 0.7834 & 0.7834 \\
\hline 3.75 & 0.75 & 0.6615 & 0.7910 & 0.7910 \\
\hline 4.00 & 0.75 & 0.6629 & 0.7975 & 0.7975 \\
\hline 4.25 & 0.75 & 0.6639 & 0.8029 & 0.8029 \\
\hline 4.50 & 0.75 & 0.6647 & 0.8074 & 0.8074 \\
\hline 4.75 & 0.75 & 0.6652 & 0.8113 & 0.8113 \\
\hline 5.00 & 0.75 & 0.6656 & 0.8146 & 0.8146 \\
\hline 5.25 & 0.75 & 0.6659 & 0.8173 & 0.8173 \\
\hline 5.50 & 0.75 & 0.6661 & 0.8197 & 0.8197 \\
\hline 5.75 & 0.75 & 0.6662 & 0.8217 & 0.8217 \\
\hline 6.00 & 0.75 & 0.6664 & 0.8234 & 0.8234 \\
\hline 6.25 & 0.75 & 0.6664 & 0.8249 & 0.8249 \\
\hline 6.50 & 0.75 & 0.6665 & 0.8261 & 0.8261 \\
\hline 6.75 & 0.75 & 0.6665 & 0.8271 & 0.8271 \\
\hline 7.00 & 0.75 & 0.6666 & 0.8280 & 0.8280 \\
\hline 7.25 & 0.75 & 0.6666 & 0.8288 & 0.8288 \\
\hline 7.50 & 0.75 & 0.6666 & 0.8295 & 0.8295 \\
\hline 7.75 & 0.75 & 0.6666 & 0.8300 & 0.8300 \\
\hline 8.00 & 0.75 & 0.6666 & 0.8305 & 0.8305 \\
\hline 8.25 & 0.75 & 0.6666 & 0.8309 & 0.8309 \\
\hline 8.50 & 0.75 & 0.6667 & 0.8313 & 0.8313 \\
\hline 8.75 & 0.75 & 0.6667 & 0.8316 & 0.8316 \\
\hline 9.00 & 0.75 & 0.6667 & 0.8318 & 0.8318 \\
\hline 9.25 & 0.75 & 0.6667 & 0.8320 & 0.8320 \\
\hline 9.50 & 0.75 & 0.6667 & 0.8322 & 0.8322 \\
\hline 9.75 & 0.75 & 0.6667 & 0.8324 & 0.8324 \\
\hline 10.00 & 0.75 & 0.6667 & 0.8325 & 0.8325 \\
\hline & & & & \\
\hline
\end{tabular}


Table 3: Performance Tables for Shell and Tube Heat Exchanger $\left(C_{r}=1.0\right)$

\begin{tabular}{|c|c|c|c|c|}
\hline \multicolumn{5}{|c|}{$\mathrm{Cr}=1.0$} \\
\hline NTU & $\mathrm{Cr}$ & $\varepsilon$ & & \\
\hline & & 1 Shell Pass & 2 Shell Passes & 4 Shell Passes \\
\hline 0.1 & 1 & 0.0908 & 0.0909 & 0.0909 \\
\hline 0.25 & 1 & 0.1986 & 0.1998 & 0.1998 \\
\hline 0.5 & 1 & 0.3250 & 0.3316 & 0.3316 \\
\hline 0.75 & 1 & 0.4082 & 0.4239 & 0.4239 \\
\hline 1 & 1 & 0.4641 & 0.4912 & 0.4912 \\
\hline 1.25 & 1 & 0.5022 & 0.5417 & 0.5417 \\
\hline 1.5 & 1 & 0.5284 & 0.5806 & 0.5806 \\
\hline 1.75 & 1 & 0.5465 & 0.6109 & 0.6109 \\
\hline 2 & 1 & 0.5592 & 0.6350 & 0.6350 \\
\hline 2.25 & 1 & 0.5680 & 0.6542 & 0.6542 \\
\hline 2.5 & 1 & 0.5742 & 0.6697 & 0.6697 \\
\hline 2.75 & 1 & 0.5785 & 0.6823 & 0.6823 \\
\hline 3 & 1 & 0.5816 & 0.6926 & 0.6926 \\
\hline 3.25 & 1 & 0.5837 & 0.7011 & 0.7011 \\
\hline 3.5 & 1 & 0.5852 & 0.7080 & 0.7080 \\
\hline 3.75 & 1 & 0.5862 & 0.7138 & 0.7138 \\
\hline 4 & 1 & 0.5870 & 0.7186 & 0.7186 \\
\hline 4.25 & 1 & 0.5875 & 0.7225 & 0.7225 \\
\hline 4.5 & 1 & 0.5879 & 0.7258 & 0.7258 \\
\hline 4.75 & 1 & 0.5881 & 0.7285 & 0.7285 \\
\hline 5 & 1 & 0.5883 & 0.7308 & 0.7308 \\
\hline 5.25 & 1 & 0.5884 & 0.7327 & 0.7327 \\
\hline 5.5 & 1 & 0.5885 & 0.7343 & 0.7343 \\
\hline 5.75 & 1 & 0.5886 & 0.7357 & 0.7357 \\
\hline 6 & 1 & 0.5886 & 0.7368 & 0.7368 \\
\hline 6.25 & 1 & 0.5887 & 0.7377 & 0.7377 \\
\hline 6.5 & 1 & 0.5887 & 0.7385 & 0.7385 \\
\hline 6.75 & 1 & 0.5887 & 0.7391 & 0.7391 \\
\hline 7 & 1 & 0.5887 & 0.7397 & 0.7397 \\
\hline 7.25 & 1 & 0.5887 & 0.7401 & 0.7401 \\
\hline 7.5 & 1 & 0.5887 & 0.7405 & 0.7405 \\
\hline 7.75 & 1 & 0.5887 & 0.7408 & 0.7408 \\
\hline 8 & 1 & 0.5887 & 0.7411 & 0.7411 \\
\hline 8.25 & 1 & 0.5887 & 0.7413 & 0.7413 \\
\hline 8.5 & 1 & 0.5887 & 0.7415 & 0.7415 \\
\hline 8.75 & 1 & 0.5887 & 0.7417 & 0.7417 \\
\hline 9 & 1 & 0.5887 & 0.7418 & 0.7418 \\
\hline 9.25 & 1 & 0.5887 & 0.7419 & 0.7419 \\
\hline 9.5 & 1 & 0.5887 & 0.7420 & 0.7420 \\
\hline 9.75 & 1 & 0.5887 & 0.7421 & 0.7421 \\
\hline 10 & 1 & 0.5887 & 0.7422 & 0.7422 \\
\hline
\end{tabular}

From the developed tables, it is very evident that the maximum performance of the heat exchanger is obtained at a capacity rate ratio of zero, i.e., while one of the fluid is undergoing a phase change. Likewise, for a given overall NTU, increasing the number of shell passes beyond 2 produces no improvement in the performance of the heat exchanger. It can also be observed that for any given pass and capacity rate ratio, there exists a threshold NTU, beyond which increasing the NTU produces very minimal effect in the performance of the heat exchanger. Needless to mention, this aspect will in turn help the engineers to design a heat exchanger that is of compact size, incurring lower cost, having lightweight, being easy to manufacture, and having the required effectiveness.

The Reynolds number for the tube side fluid, (i.e.) the hot oil, in the shell and tube heat exchanger can be determined as follows [13] 


$$
\operatorname{Re}=\frac{\rho \mathrm{VD}}{\mu}
$$

Herein, it is desired to maintain a flow velocity less than $3 \mathrm{~m} / \mathrm{s}$ such that the pressure drop in the tubes is kept at a reasonable level. The selection of a suitable pipe material and pipe diameter shall be discussed in the following sections. The Prandtl number for oil may be calculated as follows [13]

$$
\mathrm{P}_{\mathrm{r}}=\frac{\mathrm{C}_{\mathrm{p}} \times \mu}{\mathrm{K}}
$$

Assuming fully developed turbulent flow, the Nusselt number for tube side may be determined as [13]

$$
\mathrm{Nu}=0.023 \times \mathrm{R}_{\mathrm{e}}^{0.8} \times \mathrm{P}_{\mathrm{r}}^{\mathrm{n}}
$$

Recognize that hot oil (tube side fluid) has to be heated to a required temperature and therefore " $n$ " is set at 0.4 . The Nusselt number may also given as [13]

$$
\mathrm{Nu}=\frac{\mathrm{h}_{\mathrm{i}} \times \mathrm{D}}{\mathrm{K}_{\mathrm{oil}}}
$$

Employing Equations (10) and (11) the internal heat transfer coefficient may be determined.

For the shell side of the heat exchanger, the external heat transfer coefficient is assumed from the available data in the literature. For air free condensing steam, the heat transfer coefficient may be given $[13,14,15]$ as $h_{o}=8511.7 \mathrm{~W} / \mathrm{m}^{2} \mathrm{~K}$. Therefore, ignoring fouling resistances, and conduction resistances, the overall heat transfer coefficient may be given as [13]

$$
\frac{1}{\mathrm{U}_{\mathrm{o}}}=\frac{1}{\mathrm{~h}_{\mathrm{i}}}+\frac{1}{\mathrm{~h}_{\mathrm{o}}}
$$

The NTU of a heat exchanger can also be described as [13]

$$
\mathrm{NTU}=\frac{\mathrm{U}_{\circ} \times \mathrm{A}_{\circ}}{\mathrm{C}_{\min }}
$$

Therefore, from equation (13), the required surface area of the heat exchanger can be readily determined.

The total mass flow rate of hot oil may be given as

$$
\dot{\mathrm{m}}=\rho \mathrm{A}_{\mathrm{i}} \mathrm{V} * \mathrm{~N}_{\text {tubes }}
$$

Therefore, from the above equation, the required number of tubes can be readily determined. The required surface area for the heat exchanger can be given as

$$
\mathrm{A}_{\circ}=\pi \times \mathrm{D} \times[\mathrm{L}] \times \mathrm{N}_{\text {tubes }} \times \mathrm{N}_{\text {pass }}
$$


The tubes are available in standard sizes (diameter and lengths). Employing Equation (15), the required number of tube passes for the heat exchanger can be determined.

If log mean temperature difference (LMTD) approach were to be used, the rate of heat transfer may be described as [12]

$$
\mathrm{Q}=\mathrm{U}_{\mathrm{o}} \mathrm{A}_{0} \Delta \mathrm{T}_{1 \mathrm{~m}}
$$

The log-mean temperature difference is the effective mean temperature difference between the tube wall and the hot oil. In this instance it is defined as [13]

$$
\Delta \mathrm{T}_{\ell \mathrm{m}}=\frac{\left(\mathrm{T}_{\mathrm{w}}-\mathrm{T}_{\text {oil,in }}\right)-\left(\mathrm{T}_{\mathrm{w}}-\mathrm{T}_{\text {oil }, \text { out }}\right)}{\ln \left(\frac{\mathrm{T}_{\mathrm{w}}-\mathrm{T}_{\text {oil }, \text { in }}}{\mathrm{T}_{\mathrm{w}}-\mathrm{T}_{\text {oil }, \text { out }}}\right)}
$$

Here the tube wall temperature $\left(\mathrm{T}_{\mathrm{w}}\right)$ is maintained at the condensing temperature of $300 \mathrm{lbf} / \mathrm{in}^{2}$ steam and $\mathrm{T}_{\mathrm{oil}, \mathrm{in}} \&$ $\mathrm{T}_{\text {oil,out }}$ correspond to the inlet and exit temperatures of the hot oil. For LMTD approach the required heat transfer surface area is determined by employing Equation (16) and the required number of tube passes is then determined by employing Equation (15).

The tube pitch and bundle diameter based on tube diameter may be estimated as follows [14]

$$
\begin{aligned}
& \mathrm{p}_{\mathrm{t}}=1.25 \times \mathrm{D} \\
& \mathrm{D}_{\mathrm{b}}=\mathrm{D}\left[\frac{\mathrm{N}_{\text {tube }}}{\mathrm{K}_{1}}\right]^{\frac{1}{\mathrm{n}_{1}}}
\end{aligned}
$$

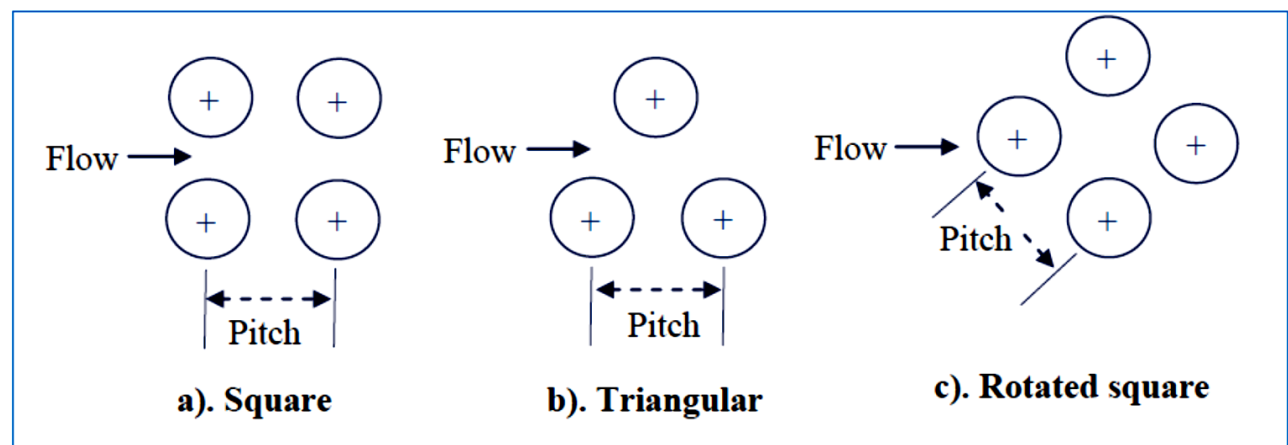

Figure 4: Tube Patterns [13] 
Table 4: Constants for Determination of Tube Bundle Diameter [14]

\begin{tabular}{|l|l|l|l|l|l|}
\hline \multicolumn{7}{|c|}{ Triangular Pitch $\mathrm{p}_{\mathrm{t}}=1.25 \mathrm{~d}_{0}$} \\
\hline Number Passes & 1 & 2 & 4 & 6 & 8 \\
\hline $\mathrm{K}_{1}$ & 0.319 & 0.249 & 0.175 & 0.0743 & 0.0365 \\
\hline $\mathrm{n}$ & 2.142 & 2.207 & 2.285 & 2.499 & 2.675 \\
\hline
\end{tabular}

\begin{tabular}{|l|l|l|l|l|l|}
\hline \multicolumn{7}{|c|}{ Square Pitch $p_{\mathrm{t}}=1.25 \mathrm{~d}_{\mathrm{o}}$} \\
\hline Number Passes & 1 & 2 & 4 & 6 & 8 \\
\hline $\mathrm{K}_{1}$ & 0.215 & 0.156 & 0.158 & 0.0402 & 0.0331 \\
\hline $\mathrm{n}$ & 2.207 & 2.291 & 2.263 & 2.617 & 2.643 \\
\hline
\end{tabular}

From [13], it can be seen either triangular or a square or a rotated square arrangement can be chosen for the design of the tube bundle. For a triangular pitch, the constants for $\mathrm{n}_{1}$ and $\mathrm{K}_{1}$ can be chosen as 2.142 and 0.319 respectively.

The shell inside diameter may be given as [14]

$\mathrm{D}_{\mathrm{si}}=\mathrm{D}_{\mathrm{b}}+$ clearance

The clearance between the shell inside diameter and the tube bundle can be determined from Figure 5, assuming pull through floating head [14].

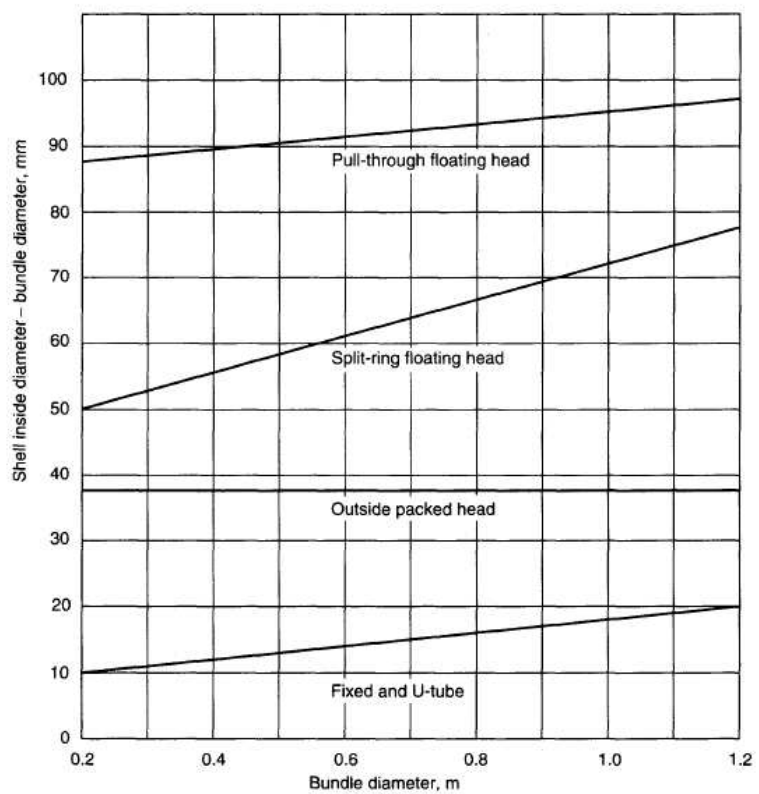

Figure 5: Tube Bundle Clearance [14]

Baffles in shell and tube heat exchanger, enhance the rate of heat transfer by providing mixing and by making the flow turbulent. Cut segmented baffle is the most popular kind and therefore a cut segmented baffle is chosen for this project.

The baffle spacing and the number of baffles can be determined as follows [14]

$\mathrm{B}_{\mathrm{s}}=0.4 \mathrm{D}_{\mathrm{si}}$

No.Baffles $=\frac{\mathrm{L}}{\mathrm{B}_{\mathrm{s}}}$ 
where $\mathrm{L}$ is the length of the tube.

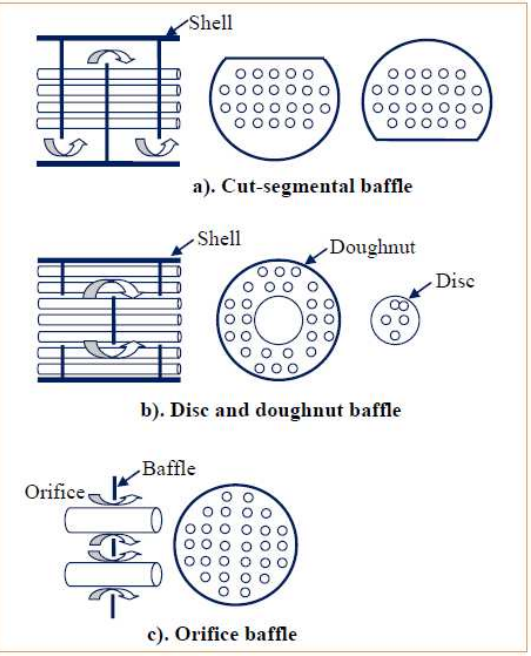

Figure 6: Kinds of Heat Exchanger Baffles [14]

\section{Design of Shell and Tube Heat Exchanger}

Using the equations described in the previous section, a MATLAB model was developed to design a shell and tube heat exchanger. $\varepsilon$-NTU approach and LMTD approach were considered in the design analysis. The first step in the design analysis is to choose an appropriate NTU corresponding to the required HX effectiveness and capacity rate ratio. Performance tables and charts were used to select an appropriate NTU for the heat exchanger. Thereafter, the overall heat transfer coefficient was computed. Using NTU and the overall heat transfer coefficient the required surface area of the heat exchanger was determined. The required tube length, tube diameter and tube passes were then extrapolated from the heat exchanger surface area.

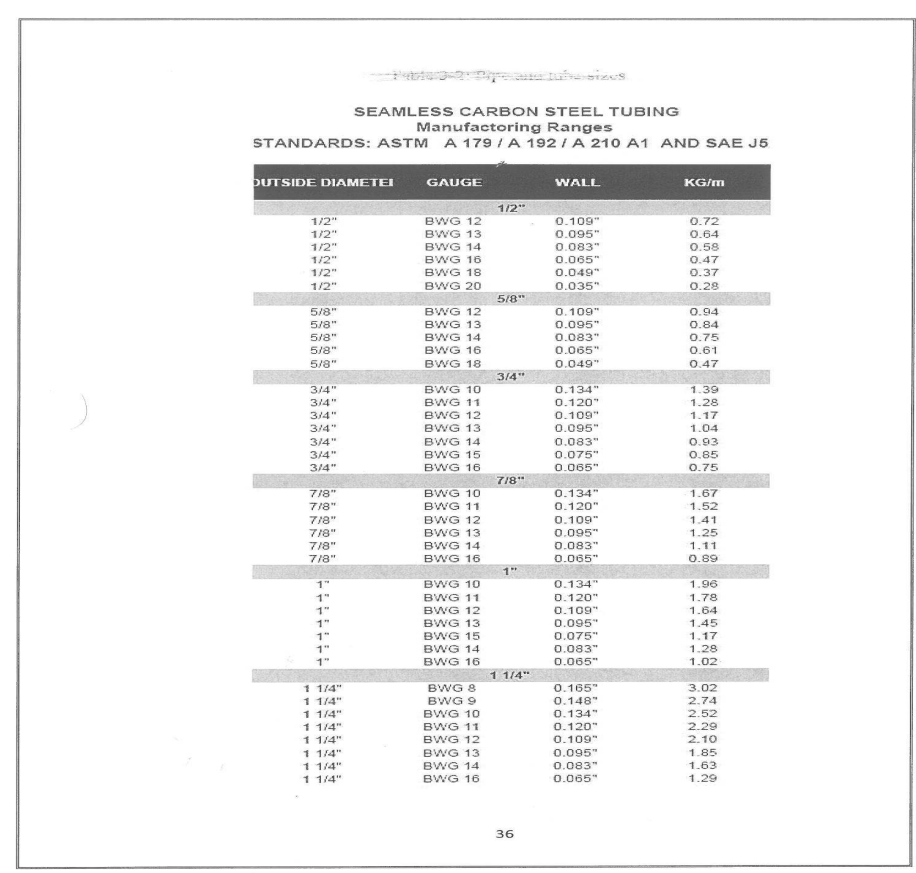

Figure 7: Tube Thickness Chart [14] 
As described in Figure 7, it is a common practice to install tube sizes of $1 / 2$ in, 5/8 in, 3/4 in, 7/8 in, and 1 in in shell and tube heat exchangers. Tubes usually come in $6 \mathrm{ft}, 8 \mathrm{ft}, 12 \mathrm{ft}, 16 \mathrm{ft}$ and $20 \mathrm{ft}$ tube lengths. For the current analysis, $3 / 4$ in carbon steel tube having a wall thickness 16 BWG and a length of $6 \mathrm{ft}$ was chosen. Since it is required to keep the pressure drop in the tubes under acceptable limits, hot oil velocity in tubes was assumed as $3 \mathrm{~m} / \mathrm{s}$. In industries, it is a common accepted practice to maintain the tube velocity under $6 \mathrm{~m} / \mathrm{s}$.

Based on the available data, requirements and assumptions the MATLAB code computed the design of shell and tube heat exchanger. Figures 8 and 9 describe the details of the shell and tube heat exchanger.

\begin{tabular}{|l|l|l|}
\hline Data & 76.67 & ${ }^{\circ} \mathrm{C}$ \\
\hline Hot oil supply temperature & 93.33 & ${ }^{\circ} \mathrm{C}$ \\
\hline Required hot oil temperature & 20.68 & $\mathrm{bar}$ \\
\hline Steam pressure & 214.00 & ${ }^{\circ} \mathrm{C}$ \\
\hline Temperature of sataurated steam & 3.15 & $\mathrm{~kg} / \mathrm{s}$ \\
\hline Mass flow rate of oil & 761.00 & $\mathrm{~kg} / \mathrm{m}^{3}$ \\
\hline Density of oil & 2258.00 & $\mathrm{~kJ} / \mathrm{kg} \cdot \mathrm{K}$ \\
\hline Specific heat at constant pressure $\mathrm{C}_{\mathrm{p}}(\mathrm{oil})$ & 0.13 & $\mathrm{~W} / \mathrm{mK}$ \\
\hline Thermal conductivity $\mathrm{K}$ (oil) & 0.0012 & $\mathrm{~N}-\mathrm{s} / \mathrm{m}^{2}$ \\
\hline Dynamic viscosity $\mu$ & 1882.60 & $\mathrm{~kJ} / \mathrm{kg}$ \\
\hline Latent heat of steam $\mathrm{h}_{\mathrm{fg}} @ 20.68(\mathrm{bar})$ & 118497.58 & $\mathrm{~W}$ \\
\hline Required rate of heat transfer for oil Q & 0.06 & $\mathrm{~kg} / \mathrm{s}$ \\
\hline Required mass flow rate of steam & 7112.70 & $\mathrm{~W} / \mathrm{k}$ \\
\hline Minimum capacity rate $\mathrm{C}_{\min }(\mathrm{oil})$ & 0.12 & \\
\hline Required $\mathrm{HX}$ Effectivness $\varepsilon$ & 0.13 & \\
\hline Required NTU & & \\
\hline
\end{tabular}

\begin{tabular}{|l|l|l|}
\hline HX Design; $\varepsilon$-NTU Approach & & \\
\hline Tube diameter OD $(3 / 4$ in) & 0.0191 & $\mathrm{~m}$ \\
\hline Wall thickness $(0.065 \mathrm{in})$ & 0.0017 & $\mathrm{~m}$ \\
\hline Tube diameter ID & 0.0157 & $\mathrm{~m}$ \\
\hline Hot oil velocity in tubes (assume) & 3 & $\mathrm{~m} / \mathrm{s}$ \\
\hline Reynolds \# for hot oil & 30729 & \\
\hline Prandtl \# for hot oil & 19.9 & \\
\hline Exponent "n" for heating & 0.4 & \\
\hline Nusselt \# for hot oil & 295.8 & \\
\hline Internal heat transfer coefficient $\mathrm{h}_{\mathrm{i}}$ & 2498.1 & $\mathrm{~W} / \mathrm{m}^{2} \mathrm{~K}$ \\
\hline External heat transfer coefficient $\mathrm{h}_{\circ}$ & 8511.7 & $\mathrm{~W} / \mathrm{m}^{2} \mathrm{~K}$ \\
\hline Overall heat transfer coefficient $\mathrm{U}_{\circ}$ & 1931.3 & $\mathrm{~W} / \mathrm{m}^{2} \mathrm{~K}$ \\
\hline Required HX surface area $\mathrm{A}_{\circ}$ & 0.4788 & $\mathrm{~m}^{2}$ \\
\hline Tube length $(6$ ft) & 1.8 & $\mathrm{~m}$ \\
\hline Required number of tubes & 7.08 & \\
\hline Required number of tubes (corrected) & 7 & \\
\hline Required number of tube passes & 0.75 & \\
\hline Required number of tube passes (corrected) & 1 & \\
\hline
\end{tabular}

\begin{tabular}{|l|l|l|}
\hline HX Design; LMTD Approach & & \\
\hline Tube diameter OD (3/4 in) & 0.0191 & $\mathrm{~m}$ \\
\hline Wall thickness (0.065 in) & 0.0017 & $\mathrm{~m}$ \\
\hline Tube diameter ID & 0.0157 & $\mathrm{~m}$ \\
\hline Hot oil velocity in tubes (assume) & 3 & $\mathrm{~m} / \mathrm{s}$ \\
\hline Reynolds \# for hot oil & 30729 & \\
\hline Prandtl \# for hot oil & 19.9 & \\
\hline Exponent "n" for heating & 0.4 & \\
\hline Nusselt \# for hot oil & 295.8 & \\
\hline Internal heat transfer coefficient $\mathrm{h}_{\mathrm{i}}$ & 2498.1 & $\mathrm{~W} / \mathrm{m}^{2} \mathrm{~K}$ \\
\hline External heat transfer coefficient $\mathrm{h}_{\circ}$ & 8511.7 & $\mathrm{~W} / \mathrm{m}^{2} \mathrm{~K}$ \\
\hline Overall heat transfer coefficient $\mathrm{U}_{\circ}$ & 1931.3 & $\mathrm{~W} / \mathrm{m}^{2} \mathrm{~K}$ \\
\hline Log Mean Temp Diff (LMTD) & 128.8 & $\mathrm{~K}$ \\
\hline Required HX surface area $\mathrm{A}_{\circ}$ & 0.4763 & $\mathrm{~m}^{2}$ \\
\hline Tube length (6 ft) & 1.8 & $\mathrm{~m}$ \\
\hline Required number of tubes & 7.08 & \\
\hline Required number of tubes (corrected) & 7 & \\
\hline Required number of tube passes & 0.75 & \\
\hline Required number of tube passes (corrected) & 1 & \\
\hline
\end{tabular}

Figure 8: Shell and Tube Heat Exchanger Design using \&-NTU and LMTD Approach

It can be clearly seen that the results from LMTD and $\varepsilon$-NTU approach are in close comparison. In most scenarios, it is entirely up to the engineer to choose an appropriate methodology while designing a heat exchanger. In this work, since there is a phase change in the external fluid (steam), there is virtually no difference between employing a parallel or a counter flow heat exchanger.

However, for heat exchangers wherein both fluids are undergoing sensible heat transfer and operating under steady state conditions, counter flow heat exchangers tend to provide a better rate of heat transfer as compared parallel flow heat exchangers. Yet, parallel flow is still preferred over counter flow in situations where the heat exchanger is subjected to transient conditions. 
Figure 9 describes the overall design and description of the shell and tube heat exchanger. Herein, it is assumed that steam has abundant mass flow rate and the required amount of steam for the heating purposes is controlled by a control valve. However, by employing energy balance, the required amount of steam can be computed. This information can be useful while selecting a steam trap for the steam side of the heat exchanger.

\begin{tabular}{|l|c|c|}
\hline Item & Shell Side & Tube Side \\
\hline Fluid & Steam & Hot Oil \\
\hline Inlet Temp $\left({ }^{\circ} \mathbf{C}\right)$ & 214 & 76.7 \\
\hline Discharge Temp $\left({ }^{\circ} \mathbf{C}\right)$ & 214 & 93.3 \\
\hline Mass flow rate $(\mathbf{k g} / \mathbf{s})$ & 0.063 & 3.15 \\
\hline Heat Transfer $(\mathbf{k W})$ & 118.5 & 118.5 \\
\hline \# of passes & 1 & 1 \\
\hline Material & Carbon Steel & Carbon Steel \\
\hline Diameter $($ in) & 7 & 0.75 \\
\hline
\end{tabular}

\begin{tabular}{|l|c|}
\hline Item & Specification \\
\hline Required NTU & 0.13 \\
\hline Heat transfer surface area $\left.\mathbf{( m}^{\mathbf{2}}\right)$ & 0.47 \\
\hline Flow velocity through tubes $(\mathbf{m} / \mathbf{s})$ & 3 \\
\hline Number of tubes & 7 \\
\hline Length of tubes (ft) & 6 \\
\hline Tube layout & Triangular \\
\hline Tube pitch (in) & 0.9375 \\
\hline Baffles type & Cut-Segmented \\
\hline Baffles material & Carbon Steel \\
\hline Baffle spacing (in) & 2.55 \\
\hline \# of baffles & 28 \\
\hline
\end{tabular}

Figure 9: Design and Description of the Shell and Tube Heat Exchanger

\section{CONCLUSIONS}

This paper reviews the fundamental analytical techniques in the design of a shell and tube heat exchanger. $\varepsilon$-NTU and LMTD are very popular analytical methods in the design of a heat exchanger. Several variants of these methods have also been developed. It must be recognized all these methods yield similar results and it is entirely up to the designer to choose an appropriate technique in the design of the heat exchanger.

$\varepsilon$-NTU is more flexible as it can be used when the fluid discharge temperatures are unknown. Such a flexibility is not available in the LMTD method as the design procedure becomes iterative in the absence of fluid discharge 
temperatures.

However, the main ingredient in the design process is the proper selection of NTU and capacity rate ratio as it is these two parameters that indirectly dictate the performance, size, weight, capital and operating cost of the heat exchanger. In most cases, the determination of NTU requires extensive calculations, which could be time consuming. The developed charts and tables saves time and help the engineers to select the required NTU and capacity rate ratio without having to perform heavy calculations. Once these two parameters are estimated, the designer knows the boundary and can readily extrapolate the detailed design of the heat exchanger.

Likewise, it is equally important for the technical engineers to understand the heat exchanger equipment so that it is operated and maintained within its performance range. In any process industry, based on the demand, the throughput has to be adjusted on a regular basis. This will force the heat exchanger to deviate from its original design condition. Performance charts and tables can aid the engineers in such situations.

\section{REFERENCES}

1. Tahery, A.A., Khalilarya, S., Jafarmadar, S., 2017. "Effectively designed shell-tube heat exchangers considering cost minimization and energy management”, Heat Transfer-Asian Research, Volume 46, Issue 8, Pages 1488-1498.

2. Hadidi, A., Hadidi, M., Nazari, A., 2013. "A new design approach for shell-and-tube heat exchangers using imperialist competitive algorithm (ICA) from economic point of view”, Energy Conversion and Management, Volume 67, Pages 66-74.

3. Şencan Şahin, A., Kiliç, B., Kiliç, U., 2011. "Design and economic optimization of shell and tube heat exchangers using Artificial Bee Colony (ABC) algorithm”, Energy Conversion and Management, Volume 52, Issue 11, Pages 3356-3362.

4. Eryener, D., 2006. "Thermoeconomic optimization of baffle spacing for shell and tube heat exchangers", Energy Conversion and Management, Volume 47, Issue 11-12, Pages 1478-1489.

5. Azar, R.T., Khalilarya, S., Jafarmadar, S., Ranjbar, F., 2017. "Modeling for Shell-Side Heat Transfer Coefficient and Pressure Drop of Helical Baffle Heat Exchangers", Heat Transfer Engineering, Volume 38, Issue 2, Pages 265-277.

6. Muralikrishna, K., Shenoy, U.V., 2000. "Heat exchanger design targets for minimum area and cost”, Chemical Engineering Research and Design, Volume 78, Issue 2, Pages 161-167.

7. Qashqaei, A., \& Asl, R. G. (2015). Numerical Modeling And Simulation Of Copper Oxide Nanofluids Used In Compact Heat Exchangers. International Journal of Mechanical Engineering, 4(2), 1-8.

8. Caputo, A.C., Pelagagge, P.M., Salini, P., 2008. "Heat exchanger design based on economic optimisation”, Applied Thermal Engineering, Volume 28, Issue 10, Pages 1151-1159.

9. Serna, M., JimÉnez, A., 2004. "An efficient method for the design of shell and tube heat exchangers", Heat Transfer Engineering, Volume 25, Issue 2, Pages 5-16.

10. Wang, Q., Chen, G., Chen, Q., Zeng, M., 2010. "Review of Improvements on shell-and-tube heat exchangers with helical baffles", Heat Transfer Engineering, Volume 31, Issue 10, Pages 836-853.

11. Bell, K.J., 2004. "Heat exchanger design for the process industries", Journal of Heat Transfer, Volume 126, Issue 6, Pages $877-885$

12. Owaid, A. I., Tariq, M., Issa, H., Sabeeh, H., \& Ali, M. The Heat Losses Experimentally in the Evacuated Tubes Solar Collector System in Baghdad-Iraq Climate. 
13. Silaipillayarputhur, K., Al Mughanam, T., Al Mojil, A., Al Dhmoush, M., 2017. “Analytical and Numerical Design Analysis of Concentric Tube Heat Exchangers - A Review", Volume 272, Issue 1, 21 December 2017, Article number 012006, IOP Conference Series: Materials Science and Engineering, 2017 4th International Conference on Mechanical, Materials and Manufacturing, ICMMM 2017; Atlanta; United States; 25 October 2017 through 27 October 2017; Code 133100.

14. Silaipillayarputhur, K., Al Mughanam, T., 2018. "Performance charts for multi-pass parallel cross-flow heat exchangers", Volume 7, Issue 5, 1 September 2018, Pages 478-482, International Journal of Mechanical Engineering and Robotics Research.

15. Bergman, T. L., Lavine, A. S., Incropera, F. P., and DeWitt, D. P., Fundamentals of Heat and Mass Transfer, $7^{\text {th }}$ Ed., John Wiley, Hoboken, NJ, 2011.

16. Kumar, R. S. Latent Heat Storage Material Evaluation base on AHP and Topsis for Low Temperature Solar Heating Applications.

17. Hewitt, G.F., Heat Exchanger Design Handbook New York, Begell House, 2008. ISBN: 978-1-56700-259-1, ISBN Online: 978-1-56700-422-9

18. Shawabkeh, R. A., Handout: Step-by-step for Heat Exchanger Design, DOI: 10.13140/RG.2.1.4959.6644, Researchgate.net, 2015. 